\title{
Función del espacio arquitectónico en el discurso de las exposiciones
}

\begin{abstract}
Resumen
Las formas del proceso de producción, emisión y consumo de los mensajes han venido modificándose de manera significativa con la aparición de las tecnologías digitales. La museografía no escapa de este fenómeno, en la medida en que los usuarios de los museos tienen nuevos paradigmas en la forma de consumir la información. Los museos también han venido evolucionando con respecto a su función, y cada vez más se acercan a la idea de que estos, conceptualmente, deben ir al exterior y no esperar la llegada de los visitantes. La educación es un factor que encuentra en los museos un recurso valioso para fomentar la integración y la afirmación de la identidad.

El recinto, como espacio arquitectónico, se convierte en el elemento que completa la articulación de los elementos de la exposición. Aunque, estructuralmente, su alteración en favor de un tipo de exposición no llega a ser significativa, sí llega a confirmarse que es necesario considerar el espacio como ente modificable en cuanto a la luz, los recorridos, las alturas o instalaciones utilizadas, elementos todos que se convierten en partes vivas de la arquitectura del lugar y, por tanto, determinando proporcionalidad, funcionalidad de toda la exposición.
\end{abstract}

Palabras clave: Museografía, exposiciones, arquitectura, lenguaje visual, discurso.

\section{Function of architectural space in the discourse of exhibitions}

\begin{abstract}
The forms of production, emission and consumption process of messages have been modified significantly with the advent of digital technologies. Museography doesn't escape to this phenomenon, as long as the users
\end{abstract}

Luis Cumpa González Arquitecto. Profesor e investigador en la Universidad Nacional Mayor de San Marcos. 
of the museums have new paradigms in the way of consume information. The museums have also been developing with regard to their function and increasingly come to the idea that they, conceptually, must be outside and not just wait visitors. Education is a factor that founds in museums a valuable resource to promote the integration and assertion of identity.

The enclosure, the architectonic place becomes the element that completes the articulation of the elements of exhibition. Although structurally its variation in favor of a type of exhibition is not significant, it is clear that we must consider the space as modifiable entity based on light, tours, heights or facilities, all elements that become live part of the architecture of the place and therefore determining proportionality, functionality of the whole exhibition.

Keywords: Museography, exhibitions, architecture, visual language, discourse.

La función pedagógica que los museos están adquiriendo en los últimos ańos motiva a buscar en ellos todo tipo de elementos que intervienen en la elaboración de los discursos, sus mecanismos de organización y su manera de ser trasmitidos para que puedan tener la eficacia como mensajes.

\section{Orígenes}

Mucho ha cambiado en la función de los museos: “...las sepulturas de los grandes fueron nuestros primeros museos ... esos tesoros de armas y vajilla, vasos, diademas, cofrecillos de oro ...no se ofrecían a la mirada de los vivos ...en la mayoría de los casos estaba prohibido el acceso a las criptas ...nuestros depósitos de imágenes, entre nosotros los modernos, se exponen a la vista" " esta cita de Debray es reveladora de cuánto ha evolucionado la forma cómo los museos se han relacionado con el público. Su origen está vinculado a la preservación de la vida donde el almacenamiento se convertía en la posibilidad de la prolongación de la existencia y proponía rituales alejados de la exposición pública, a diferencia de lo que sucede hoy donde “...nosotros debemos interrumpir las nuestras

1 Régis Debray. Vida y muerte de la imagen. Paidós . Buenos Aires. 1994. 
(actividades) para visitar nuestros mausoleos”. “...en Roma, hasta el bajo imperio, la exposición en público de retratos está limitada y controlada” la restricción de la exhibición tenía un sentido sagrado en la medida en que se le asignaba un valor de perennización a quienes una vez fallecidos tenían una vida más allá de la efímera presencia presente. “...solo los muertos ilustres tienen derecho a una efigie, pues son por naturaleza influyentes y poderosos", este carácter reservado del funeral se mantuvo por mucho tiempo y específicamente alrededor de personajes vinculados al poder. Son las representaciones las que empezaron a adquirir importancia cuando se convertían en sustitutos del verdadero, pero que tenían la capacidad de poseer la carga emotiva del original, así lo menciona Debray: la efigie de Francisco I preside durante cuarenta días las ceremonias de la corte “...en la copia hay más que en el original”. Las representaciones en el museo actual tienen una proyección más práctica, de función inmediata, de insertarse en las necesidades del público que se convierte en parte de la dinámica diaria y ya no solo del visitante fortuito. Esta evolución de la forma cómo se ha relacionado el museo con la sociedad podría tener una coincidencia muy cercana con la visión de Debray sobre la historia de la mirada: primero mágica, luego estética y ahora económica.

El museion, templo griego dedicado a las musas ${ }^{2}$ es el primer antecedente del museo. El interés de los conquistadores por vanagloriarse de sus éxitos en las guerras conducía a buscar objetos emblemáticos de los vencidos para mostrarlos como trofeos de guerra y progresivamente acumularlos e ir generando a la vez una suerte de conjunto de objetos clasificados por su valor religioso, militar, simbólico; proceso que después dará lugar a las colecciones quienes desarrollaron la costumbre a partir de los saqueos de Siracusa y de Corinto.

Hugues de Varine-Bohan considera que el museion y la pinakothéque son dos instituciones en las que se puede encontrar el origen de los museos; todo esto explicado por Germain Bazin . De acuerdo con de Varine-Bohan, existe una segunda forma de considerar el origen de los museos que tiene que ver con el concepto de cultura que es un ente vivo, dinámico. Y una tercera forma en la que "la iniciativa cultural desaparece... y es sustituida por la innovación tecnológica”.

2 Los Museos en el Mundo. Ed. SALVAT. Barcelona. 1973. 


\title{
Valor pedagógico de los museos
}

\begin{abstract}
"El museo es una institución terriblemente didáctica..." señala de Varine-Bohan refiriéndose al hecho de que el objeto museístico no podía ser analizado a fondo, ni ser tocado, solo para ser mostrado. La visión social del museo ha conducido a afirmar la necesidad de diversificar su función, su vinculación rígida inicial con el hecho artístico ha ido dejando paso a un concepto más abierto de su tipología. “...el museo debe abrirse a todo, a todo aquello que contribuye a la vida", esta visión social del museo plantea nuevas maneras de concebir la creación, transmisión y evaluación de las acciones del museo tanto en lo que respecta a la exposición como a su recinto.
\end{abstract}

\section{El continente}

La concepción inicial del espacio que albergaba las exposiciones ha ido modificándose al punto que, como planteaba de Varine-Bohan, ya no es un edificio necesariamente en el que se presentan los objetos, las mismas ciudades se convierten en lugares que “...tienen valor de tradición, de hábitat y de uso".

Los palacios y castillos e iglesias se convertían en los lugares donde se almacenaban las obras de arte así como familias de poder económico que mostraban en privado sus colecciones. Muchas de estas edificaciones fueron adaptadas para servir como museo, es el caso del Louvre. Los cambios sociales condujeron a una apertura de estas obras al público y, posteriormente, a la edificación de museos expresamente para exhibir estos objetos como el Museo del Prado (1785), el Museo Británico (1823) y antes, el Museo de los Uffizi en Florencia por Vassari. La necesidad de edificar museos implicó la atención por parte de arquitectos como Henry Van de Velde, Le Corbusier, Mies van der Rohe, y, recientemente, Frank Gehry, Frank Lloyd Wright, Víctor Horta.

La adaptación de las edificaciones parece tener sus límites en la medida en que evolucionan el lenguaje de las exposiciones, las tecnologías y la dinámica social. Uno de los retos de la arquitectura es establecer las posibilidades de la versatilidad del espacio arquitectónico en relación 
con el aporte de la tecnología. El invento del hormigón armado, los sistemas prefabricados, la incursión del acero, el vidrio y materiales sintéticos para coberturas y estructuras proponen no solo alternativas para las nuevas edificaciones sino para las posibles adaptaciones.

\section{Las exposiciones}

Las primeras exposiciones eran colecciones de objetos mostradas a públicos muy restringidos; progresivamente, fueron ordenándose de acuerdo con los denominadores comunes observados en los almacenes.

Fundamentalmente, eran obras de arte los objetos mostrados; a medida que va cambiando la concepción del museo, el contenido también cambia. La evolución de la pedagogía empieza a tener influencia en la función de los museos trastocando no solo su función sino su materialización en las edificaciones, en su papel como institución dentro de la ciudad.

Los cambios sociales, las influencias ideológicas globales, el avance de las nuevas tecnologías, los grandes conflictos sociales inducen a la diversificación de los motivos de las exposiciones, como los temas ecológicos, los museos llamados de La Memoria -producto de problemáticas muy sensibles en la sociedad actual- los museos de avances tecnológicos y la incorporación del sentido recreacional de sus recorridos. La nueva concepción de que el museo debe ir a la comunidad y no que ella vaya al museo implica cambios sustanciales incluso en la manera de concebir los recintos desde el punto de vista arquitectónico.

\section{El lenguaje de las exposiciones}

Hablar de lenguaje significa conocer los signos, los elementos que componen este lenguaje, su potencial, su comportamiento, su capacidad de integración así como su disposición para insertarse en una propuesta de recorrido, en ser parte indispensable en un guion museográfico y ofrecer su capacidad para transmitir de manera eficaz el mensaje que requiere la exposición. 
La concepción general planteada por la exposición deberá resumirse técnicamente en un texto donde se expresa la idea fuerza a desarrollar, es la idea rectora de la exposición, establece los lineamientos alrededor de los cuales se materializará cada uno de los elementos del lenguaje de la exposición. Esta concepción, desde el punto de vista funcional, se expresará en la palabra clave, en el concepto que se verterá en todo el recorrido. La palabra clave es concebida aquí como la materialización verbal de ese concepto y que de manera muy clara resuma la información que se va a desarrollar en toda la exposición.

Como en todo discurso, se hace necesario tener un hilo conductor de la historia, este hilo es el concepto. Los elementos visuales construyen el tejido de ese discurso. Cada elemento visual tiene su lugar, su protagonismo en el momento y en el lugar adecuados, y cada uno de ellos armonizados constituyen el discurso esperado. Sin embargo, no todos los elementos visuales tienen presencia en un mismo nivel. Algunos de ellos cobran importancia o tienen mayor presencia en algún momento del recorrido por sus propias características de enfatizar mejor la idea que se quiere transmitir y, en general, también algunos o alguno puede ser el centro de atención del discurso museístico; queda claro que no es en sí mismo el elemento el que destaca sino que hace destacar el objeto o la acción que se presenta.

En la comunicación funcional, sabemos que hay dos elementos básicos que siempre están presentes: el texto y la imagen, esto nos lo hace saber Moles y podemos suscribirlo en su totalidad en la medida en que reconozcamos que la imagen tiene un significado polisémico, es decir, que puede dar lugar a diversas interpretaciones, pues su lectura es arbitraria espacialmente, cromáticamente, conceptualmente, estéticamente; en cambio, el texto es literal, su lectura es lineal y fija el significado del mensaje otorgando la transitividad (Mc Luhan) entre el emisor y el receptor. Precisamente, aquí radica el valor de la comunicación funcional y su diferenciación de la obra artística.

Entonces, estos dos elementos son los que van a ir materializándose con las tipografías, los colores, la iluminación, las texturas, las instalaciones, las vitrinas, el sonido, la señalética, la virtualidad, etc. 


\section{El espacio, el otro factor}

En todo el recorrido de una exposición, el espacio constituye el otro factor que completa la materialización del mensaje. El espacio ${ }^{3}$ no es simplemente el ambiente donde se depositan los elementos del recorrido. El espacio ha de integrarse al discurso en toda su extensión, como cerramiento, como protector de lo exhibido, como lugar acogedor de las personas que se desplazan en ese lugar. Su acondicionamiento para cubrir cabalmente la función que le corresponde en cada exposición implica la modificación de la concepción espacial en términos de proporción, iluminación, incorporación de los conceptos abierto/ cerrado, techo/piso, inicio/fin, fijación jerarquizada de hitos, circulación vertical/horizontal ${ }^{4}$, incluso la ventilación, etc.

La adaptación del recinto será permanente en cada exposición. Esto significa que la edificación ha de soportar adaptaciones de todo tipo. Hablamos acá de una edificación que es flexible en términos funcionales y que ha sido destinada a usos de este tipo. No entraremos a la discusión sobre los museos que, por ejemplo, inicialmente fueron castillos y los que han sido concebidos expresamente a un uso especializado. Solo asumimos el espacio al que se le ha dado la posibilidad de modificarse, incluso estructuralmente, si fuera necesario.

Los creadores del recorrido de la exposición han de tener bien claro el papel del espacio arquitectónico. Su consideración ha de llevar como resultado un recorrido eficaz.

Como en todo proceso de transmisión de la información, los elementos, además del espacio, pese a que siempre están presentes y materializan el objeto de la exposición, paradójicamente, son los que menos deben quedar en la memoria del visitante. Es el mensaje el que debe quedar en la memoria de las personas. Es el concepto trabajado por los creadores del guion museístico lo que debe quedar. El mejor mensaje es el que hace que sus elementos sean los que menos se evidencien.

3 Isabel García Fernández, Luis Alonso Fernández. Diseño de exposiciones. Alianza Forma. Madrid. 2010

4 Luis Alonso Fernández. Museología y museografía. Ediciones del Serbal. España. 2006 
Los colores, la iluminación, la tipografía, las vitrinas, etc. son la materialización del discurso, pero el concepto del discurso en sí mismo es algo que está por encima de lo material. Por eso es que resulta fundamental, como se mencionaba líneas arriba en este texto, definir la idea fuerza y la palabra clave. Esto conduce necesariamente a establecer un sistema de jerarquías en el conjunto de los elementos de la exposición.

\section{Los elementos}

Los elementos básicos de la comunicación visual, el texto y la imagen, se materializan y adquieren una jerarquía sobre la base de su relación con los elementos de la exposición como la iluminación, la maqueta, el color, la forma tipográfica, las vitrinas 5 , la señalética, el sonido, la multimedia, los lenguajes interactivos ${ }^{6}$.

La determinación del elemento que guía el desarrollo del recorrido implica la asignación de preponderancia a determinados elementos en jerarquización sucesiva y complementaria, es decir, que un elemento recibe el aporte de los otros para sobresalir y tener el liderazgo visual; en el lenguaje del diseño, a esto se le denomina Centro de Impacto Visual (CIV). Una analogía con la composición bidimensional se podría hacer entre el recorrido de la exposición a lo largo de los pasillos y ambientes de la exposición desde el ingreso hasta el término de la exposición con el recorrido que hace el ojo en una página a lo largo de las denominadas líneas de composición o líneas compositivas.

Se trata de establecer recorridos donde los elementos, basados a sus atributos, van marcando puntos de atención jerarquizada a la exposición; por ejemplo, la tipografía, puede modificar su forma de letra, el tamaño, el color, de acuerdo con un grado de importancia. La iluminación, según su intensidad, direccionalidad, tipo, color, puede resaltar la atención de un objeto de la exposición, el texto de una pieza, la señalización del recorrido, la identidad de la exposición.

5 Manual de Pequeños Museos. Goethe-Institut Lima. Embajada de la República Federal de Alemania. 2005.

6 Guash, Ana María. El arte del siglo XX en sus exposiciones. 1945-1995. Ediciones del Serbal. Barcelona. 1997. 


\section{El discurso}

Todos estos factores determinan la identidad de la exposición que se expresa mediante un discurso que se ha elaborado solo para este fin.

El punto de partida de este discurso es la determinación del concepto. La idea es el hilo conductor del discurso. Esta se ha de materializar en el lenguaje bimedia que va a acompañar a los objetos en el recorrido. El concepto es el aspecto fundamental de un proyecto museístico.

En la comunicación funcional, se busca que lo elaborado como discurso por el emisor sea lo que, en este caso, el visitante de la exposición también perciba. Se espera que el discurso pueda validarse, comprobar que cumplirá los objetivos de la exposición. Al final del recorrido, el espectador debe haber incorporado su sentir del concepto tal como lo concibió su creador. Cada uno de los elementos aporta intensidad, timbre, duración, textura, claridad a cada hito del recorrido. Un conocimiento riguroso de cada uno de ellos permitirá potenciar sus atributos, así como una adecuada integración con los otros. El creador ha de tener en cuenta esto.

El espacio arquitectónico forma parte del discurso como lugar que acoge y deja viajar el discurso, le otorga placidez al recorrido, le expresa amabilidad al visitante, a la vez que no se deja percibir. Una de las características de los elementos que constituyen el discurso es su invisibilidad como tales. Su valor radica en la claridad del discurso, en la relevancia de los objetos y la información que se pretende difundir. El mejor uso que se puede dar al color, la iluminación, la tipografía, etc. es buscar que no se noten como tales.

\section{$\underline{\text { Referencias }}$}

Alonso Fernández, Luis (2006). Museología y museografia. España: Ediciones del serbal.

Debray, Régis (1994) Vida y muerte de la imagen. Buenos Aires, Argentina: Paidós.

Ediciones SALVAT (1973). Los Museos en el Mundo. Barcelona, Madrid: Ed. SALVAT. 
García Fernández, Isabel y Alonso Fernández, Luis (2010). Diseño de exposiciones. Madrid, España: Alianza Forma.

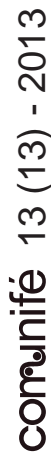

Guash, Ana María (1997). El arte del siglo XX en sus exposiciones. 19451995. Barcelona, España: Ediciones del Serbal.

Manual de Pequeños Museos (2005). Goethe-Institut Lima. Embajada de la República Federal de Alemania. 